\title{
Particulate matter and airborne fungi concentrations in schools in Athens
}

\author{
Dorizas P.V. ${ }^{1 *}$, Kapsanaki-Gotsi E. ${ }^{2}$, Assimakopoulos M.N. ${ }^{1}$, Santamouris M. ${ }^{1}$ \\ 1 Faculty of Physics, Department of Environmental Physics and Meteorology, University of \\ Athens, University Campus, Athens, 157 84, Greece \\ 2 Faculty of Biology, Department of Ecology and Systematics, University of Athens, Athens, \\ 15784 , Greece \\ *corresponding author e-mail: pdoriza@phys.uoa.gr
}

\begin{abstract}
Indoor Air Quality degradation is of exceptional concern due to the potential adverse effects indoor air pollutants have on human's health. Students are a susceptible group of people, who spend a lot of their time within classrooms. The purpose of this study is to investigate the concentration levels of particulate matter (PM) and total airborne fungi, in school classrooms. Further objective is to examine possible correlations between $\mathrm{PM}_{10}, \mathrm{PM}_{2.5}, \mathrm{PM}_{1}$, ultrafine particles (UFPs, diameter $<100 \mathrm{~nm}$ ), and airborne fungi. The measurements were performed using fully automated instrumentation. The results indicate that a lot of $\mathrm{PM}_{10}$ concentrations exceeded the proposed daily limit of $50 \mu \mathrm{g} / \mathrm{m}^{3}$. Also, in some cases the concentration of the total airborne fungi indoors, exceeded their concentration outdoors. There is evidence that certain correlations exist between PM and airborne fungi.
\end{abstract}

\section{Introduction}

In the recent years there has been a growing interest among the scientific community on the study of Indoor Air Quality (IAQ) as people spend approximately $90 \%$ of their time in indoor environments (EPA 1995a). People are largely exposed to indoor air pollutants for which there is evidence that cause adverse health effects when exceeding certain concentration thresholds. Exposures on indoor air pollutants such as UFP are linked with health effects such as asthma symptoms, allergies, respiratory and cardiovascular diseases (Pope and Dockery 2006). Airborne fungi concentrations are also related to several health problems such as irritations, infections and allergies (Pongracic et al. 2010). However, there is limited number 
of studies in the literature concerning simultaneous measurements of PM and airborne fungi.

Children are more susceptible compared to adults due to the greater air inhaled in proportion to their body weight (EPA 1995b). Students in particular spend a considerable amount of their day time in classrooms ( $>6 \mathrm{~h}$ per day) (Silvers et al. 1994). Degraded IAQ in classrooms impacts students' performance, attendance and comfort (EPA 1995b). Thus, the quality of air inside school classrooms is of primary concern.

The present study (i) measures simultaneously concentrations of both PM and total airborne fungi in classrooms of two schools, in Athens (ii) characterizes classrooms' indoor environments based on the proposed concentrations limit values by international certification bodies and (iii) examines possible correlations between PM of different aerodynamic diameters and airborne fungi.

\section{Measurement methodology and instrumentation}

Two high schools from contiguous areas outside the city center of Athens were selected in order to perform the experimental campaign. The first is placed in the Kaesariani (K) urban area away from major highway and is close to a park. The second school is in the Ymittos (Y) urban area where the traffic in the adjoining streets is moderate. The measurements started in January 2011 lasted until May 2011 and were conducted once a week fortnightly in each school. Air sample was collected from eight sampling sites $\mathrm{K} 1$ to $\mathrm{K} 8$ and $\mathrm{Y} 1$ to $\mathrm{Y} 8$ for each of the two schools ( $\mathrm{K}$ and $\mathrm{Y}$ respectively); one was the outdoor environment and the other seven were in classrooms as well as teachers' office. Certain classrooms were occupied by students during sampling.

Measurements of $\mathrm{PM}_{10}, \mathrm{PM}_{2.5}$, and $\mathrm{PM}_{1}$ in units of $\mu \mathrm{g} / \mathrm{m}^{3}$ where performed using the OSIRIS airborne particulate monitor (Turnkey Instruments Ltd). UFPs $(<100 \mathrm{~nm}$ in diameter) were measured using PTRAK (TSI, model 8525) in units of particles $/ \mathrm{cm}^{3}$. The sampling apparatus were placed at $0.8 \mathrm{~m}$ height above the floor and were synchronized to monitor with a sampling step of 1 second. The duration of each measurement per position was $10 \mathrm{~min}$.

For the recovery of airborne fungi a Burkard (Burkard Manufacturing Co. Ltd. Hertfordshire, UK) portable air sampler for agar plates was used. Three plates with Malt Agar were exposed consecutively in each sampling site for $3 \mathrm{~min} /$ plate and then incubated for 2 weeks. The colony count was corrected and expressed as colony forming units per cubic meter $\mathrm{CFU} / \mathrm{m}^{3}$.

The statistical analysis was performed using SPSS 18 statistical software package as well as data analysis Microsoft Excel 2007. Average values and distributions of the measured parameters are characterized. Spearman's and Pearson correlation coefficients were calculated amongst different pollutants in order to understand the association between the measured variables. In the statistical anal- 
ysis that follows, the average value of each 10 min measurement was taken into account.

\section{Results}

Fig. 1 left and right indicates the variation in time of $\mathrm{PM}_{10}$ concentrations at the two schools. Y-axis shows the average concentration per measurement, per sampling site, and $\mathrm{X}$-axis shows the measurement dates. Intense fluctuations appear in some cases especially at school K (Fig. 1 left K3, st.dev. =46), whereas in school $\mathrm{Y}$ the variations are smoother (Fig. 1 right Y3, st.dev. $=32$ ). The monitored classrooms were naturally ventilated and the windows were kept closed during the sampling time. Outdoor fresh air did not enter the classrooms so as to meet ventilation requirements and to remove odors and contaminants. Furthermore the increased concentrations for certain dates are possibly linked to the presence of a large number of students occupying the classrooms before or during the measurement. This could be attributed to the fact that the physical activity and presence of students may result in the resuspension of coarse particles and therefore affect their concentrations (Guo et al. 2010). However, there were cases with high concentrations but without students being present prior or during the measurement (e.g. Fig. 1 left K3, March $\left.3^{\text {rd }}\right)$. Outdoor peak values at site K8 $\left(17^{\text {th }}\right.$ and $31^{\text {st }}$ of March) are due to the high relative humidity values as precipitation was observed on certain days. In addition, in these dates strong smell of smoke was detected which have also affected the concentrations. As for school Y, measurements do not fluctuate a lot (Fig. 1 right). The exceptional peak of $\mathrm{PM}_{10}$ concentrations on the $23^{\text {rd }}$ of March of Classroom Y3 (Fig. 1 right) is due to the fact that this classroom was fully occupied by students that day right before the measurement, whose presence may have influenced the concentrations. It should be noted that this classroom was empty right before the rest of the measurement dates.

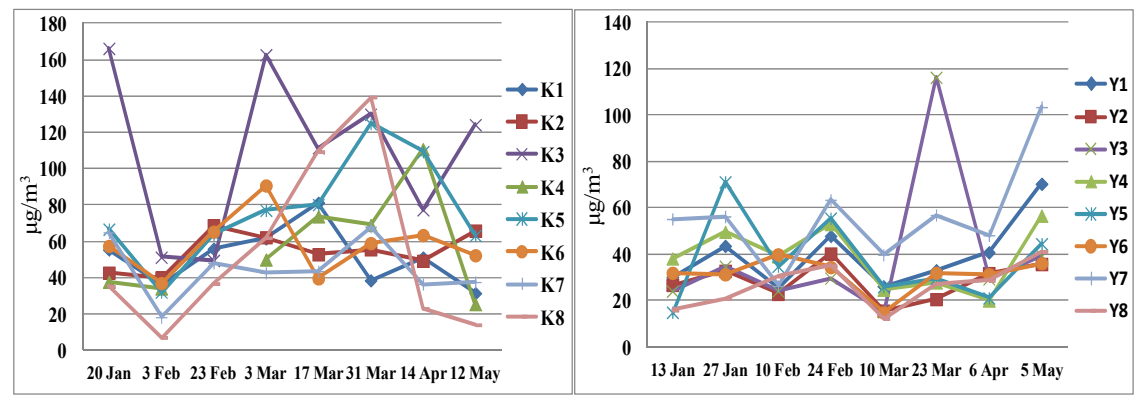

Fig. 1. $\mathrm{PM}_{10}$ concentration variation of school $\mathrm{K}$ (left) and of school $\mathrm{Y}$ (right). 
The percentages of the total average $\mathrm{PM}_{10}$ and $\mathrm{PM}_{2.5}$ values that exceed the WHO recommended 24-h limit value of $50 \mu \mathrm{g} / \mathrm{m}^{3}$ and $25 \mu \mathrm{g} / \mathrm{m}^{3}$ for school $\mathrm{K}$ are $60 \%$ and $5 \%$ respectively and for school $\mathrm{Y}$ are $17 \%$ and zero respectively.

The total concentration of the viable airborne fungi in the classrooms in each one of the schools, in several samplings is remarkably higher than that detected outdoors and this is an indication for the presence of amplification sources indoors. The mean concentration of total fungi in the seven locations sampled indoors is presented versus the concentration outdoors, for the two schools (Fig. 2).

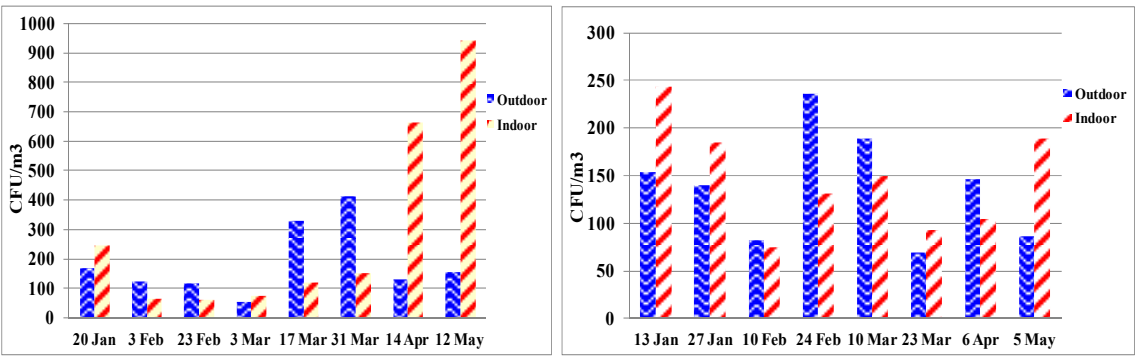

Fig. 2. Concentration of airborne fungi indoor vs outdoor in school K (left) and in school Y (right).

There is a spatio-temporal distribution in the concentration of fungi in the indoor air. The fungal load is presented in logarithmic scale (Fig. 3 left and right) in order to accommodate outliers. The concentration of fungi indoors ranged 28-548 $\mathrm{CFU} / \mathrm{m}^{3}$ excluding 4 extreme peaks in school K (Fig. 3 left) and 28-402 CFU/m $\mathrm{m}^{3}$ excluding 1 extreme peak in school Y (Fig. 3 right). There is not a universally acceptable threshold value limit for fungal concentration in relation to health impacts. It depends on several factors and mostly on the sensitivity of individuals.
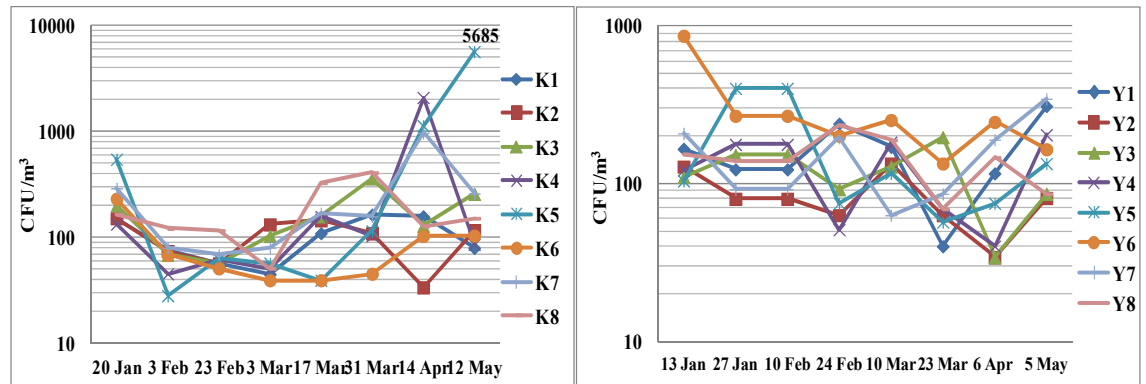

Fig. 3. Fluctuation of airborne fungi in school K (left) and in school Y (right).

Fig. 4 presents the distribution of the total indoor average concentrations of UFP for the two schools in box plots. The centre line of the box is the median; the outer lines of the box represent $25^{\text {th }}$ and $75^{\text {th }}$ percentile and the dotted values are outliers. It can be seen that UFP concentrations in school Y are greater than the 
corresponding ones of school $\mathrm{K}$ and also present a stronger dispersion around the mean value. Vehicular emissions from the adjoining streets could have influenced the indoor concentrations of $\mathrm{Y}$ school. This is not consistent with the findings for school $\mathrm{K}$ which seemed to be mostly charged by larger particles.

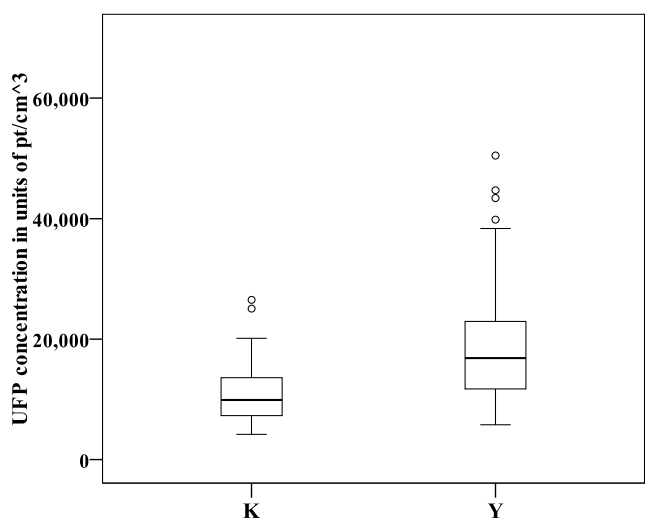

Fig. 4. UFP concentrations in particles per cubic centimeter for the two schools ( $\mathrm{K}$ and $\mathrm{Y})$.

As expected, from the statistical analysis that was performed it was found that $\mathrm{PM}_{10}$ are significantly correlated to $\mathrm{PM}_{2.5}$ for both of the schools (Pearson correlation coefficient was approx. 0.7 at the 0.01 level for both schools). Thus, is in agreement with the findings of other research groups (Gaidajis and Angelakoglou 2009). As of the correlation between airborne fungi and PM, the statistical analysis shows that airborne fungi positively correlated to UFP for both schools. However, the correlations were weak as the correlation coefficients lie below 0.5 ( 0.310 and 0.356 at the 0.05 and 0.01 levels for schools $\mathrm{K}$ and $\mathrm{Y}$ respectively). It was found that $\mathrm{PM}_{10}$ concentrations correlated to the total fungi only in school $\mathrm{Y}$ (Spearman's correlation coefficient equal to 0.268 at the 0.05 level).

\section{Concluding remarks}

A great percentage of the $\mathrm{PM}_{10}$ measurements exceeded the recommended limit values especially in school $\mathrm{K}$. School $\mathrm{K}$ is rather surcharged from coarse particles compared to Y school. However, school Y had increased concentrations of particles in the ultrafine range. PM concentrations increased with the presence of students and smoke and were influenced by outdoor vehicle emissions. Some correlation coefficients found to be statistically significant; however, there could not be found a generalized correlation pattern for both schools. Further research should be made on the simultaneous measurements of PM and airborne fungi for longer 
measurement periods in order to develop a model for predicting the levels and interrelationships between PM and total airborne fungi.

Acknowledgments The authors would like to acknowledge all of the participants in the experimental campaign. In particular, we gratefully acknowledge the contribution of Antoniou Nikos, Antonopoulos George, Demertzi Marialena and Papakonstantinou Konstantinos. This research has been partly co-financed by the European Union (European Social Fund - ESF) and Greek national funds through the Operational Program "Education and Lifelong Learning" of the National Strategic Reference Framework (NSRF) - Research Funding Program: Heracleitus II. Investing in knowledge society through the European Social Funding.

\section{References}

EPA United States Environmental Protection Agency, Office of Radiation and Indoor Air, U S Consumer Product Safety Commission (1995a) The Inside Story: A Guide to Indoor Air Quality. U S Environ Prot Agency, Office of Air and Radiat, Minnesota

EPA United States Environmental Protection Agency (1995b) Indoor Air Quality tools for schools. U S Environ Prot Agency, Washington

Gaidajis G, and Angelakoglou K (2009) Indoor air quality in university classrooms and relative environment in terms of mass concentrations of particulate matter. J Environ Sci Heal A 44:1227-1232. doi: 10.1080/10934520903139936

Guo H, Morawska L, He C, Zhang YL, Ayoko G and Cao M (2010) Characterization of particle number concentrations and PM2.5 in a school: influence of outdoor air pollution on indoor air. Environ Sci Pollut Res 17:1268-1278. doi: 10.1007/s11356-010-0306-2

Pongracic JA, O'Connor GT, Muilenberg ML, Vaughn B, Gold DR, Kattan M, Morgan WJ, Gruchalla RS, Smartt E, Mitchell HE (2010) Differential effects of outdoor versus indoor fungal spores on asthma morbidity in inner-city children. J Allergy Clin Immun 125:593-599. doi: 10.1016/j.jaci.2009.10.036

Pope CA III, and Dockery DW (2006) Health effects of fine particulate air pollution: Lines that connect. J Air Waste Manage 56:709-742.

Silvers A, Florence BT, Rourke DL, Lorimor RJ (1994) How Children Spend Their Time A Sample Survey for Use in Exposure and Risk Assessments. Risk Anal 14:931-944. doi: $10.1111 / \mathrm{j} .1539-6924.1994 . t b 00062 . x$ 